\title{
RECICLAGEM DE PRECIPITAÇÃO NA AMAZÔNIA: UM ESTUDO DE REVISÃO
}

\author{
VINÍCIUS MACHADO ROCHA ${ }^{1}$, FRANCIS WAGNER SILVA CORREIA ${ }^{2}$, \\ PAULA ANDREA MORELLI FONSECA ${ }^{1}$
}

\author{
${ }^{1}$ Instituto Nacional de Pesquisas da Amazônia (INPA), Escritório Central do LBA, Manaus, AM, Brasil \\ ${ }^{2}$ Universidade do Estado do Amazonas (UEA), Manaus, AM, Brasil \\ vinicius@inpa.gov.br
}

Recebido Março de 2014 - Aceito Julho de 2014

\begin{abstract}
RESUMO
Este artigo traz uma perspectiva histórica da evolução do conhecimento sobre a reciclagem de precipitação e fornece uma visão crítica do estado da arte atual. São retratadas as principais fontes de umidade para a precipitação na Amazônia e o transporte de vapor d'água sobre a América do Sul. A quantificação do mecanismo de reciclagem é um indicador da importância dos processos de superfície e do clima no ciclo hidrológico, assim como da sensibilidade climática relacionada às alterações nesses processos. Os aspectos climatológicos da reciclagem na América do Sul mostram que a contribuição advectiva é mais importante para a precipitação sobre a Amazônia e o Nordeste do Brasil, ao passo que na região Centro-Sul a contribuição local tem importante papel na precipitação. Estima-se que a reciclagem de precipitação na Amazônia é da ordem de 20-35\%. A advecção de umidade domina o fornecimento de vapor d'água em grande parte da região amazônica, entretanto, o papel da evapotranspiração local na reciclagem é mais importante no setor sul da bacia. Embora os estudos sobre reciclagem tenham produzido novos conhecimentos acerca da interação entre os processos de superfície e o ciclo hidrológico, os efeitos das mudanças climáticas globais nesse mecanismo ainda não estão completamente compreendidos.
\end{abstract}

Palavras-chave: Amazônia; Reciclagem de precipitação; Transporte de umidade; Balanço de água; Interação biosfera-atmosfera.

\begin{abstract}
PRECIPITATION RECYCLING IN THE AMAZON: A REVIEW STUDY
This paper constitutes a historical perspective in the evolution of the knowledge on precipitation recycling and provides a critical view on the current state-of-the-art. The main sources of moisture for Amazon rainfall and the transport of water vapor over South America are described. The recycling mechanism quantification is an indicator of the importance of the land-surface processes and climate to the hydrological cycle, as well as climate sensitivity associated to changes in these processes. The climatological aspects of the recycling precipitation over South America shows that the advective contribution is more important for the precipitation over the Amazon basin and Brazil's Northeast, while in the Central-South region the local contribution plays an important role in the precipitation. It is estimated that the precipitation recycling in Amazon basin is 20-35\%. Over the Amazon, advection of moisture dominates the supply of atmospheric water vapor over much of the river basin but local evaporation is much more prominent over the southern region. Although the precipitation recycling studies have produced new information concerning the interaction between the land-surface processes and hydrological cycle, the effects of global climate change in this mechanism are not yet fully understood.
\end{abstract}

Keywords: Amazon Basin; Precipitation recycling; Moisture flux; Water budget; Biosphereatmosphere interaction. 


\section{INTRODUÇÃO}

A Amazônia é a única grande extensão contínua de floresta tropical úmida do mundo. Com uma área de aproximadamente 6,5 milhões de $\mathrm{km}^{2}$, que corresponde a $56 \%$ das florestas tropicais da Terra, a Amazônia desempenha um importante papel nas trocas de energia, umidade e massa entre a superfície continental e a atmosfera, fornecendo serviços ambientais fundamentais para a manutenção do clima regional e global, tais como: o armazenamento e absorção do excesso de carbono da atmosfera, o transporte de gases traço, aerossóis e vapor d'água para regiões remotas e, principalmente, a reciclagem de precipitação. A floresta amazônica também atua como uma das fontes indispensáveis de calor para a atmosfera global por meio de sua intensa evapotranspiração e liberação de calor latente de condensação na média e alta troposfera em nuvens convectivas tropicais, contribuindo na geração e manutenção da circulação atmosférica em escalas regional e global (Fisch et al., 1998; Rocha, 2001; Artaxo et al., 2005; Fearnside, 2005; Marengo, 2006; Malhi et al., 2008; Nobre et al., 2009a,b; Satyamurty et al., 2013).

No que se refere ao balanço de água, a bacia amazônica comporta-se como um sumidouro de umidade da atmosfera (precipitação maior que evapotranspiração), recebendo vapor d'água tanto do transporte de origem oceânica quanto da evapotranspiração produzida pela própria floresta tropical. Com relação à circulação regional, a Amazônia representa uma importante fonte de umidade para o Centro, Sudeste e Sul do Brasil, assim como para o norte da Argentina, incluindo a bacia do Prata, contribuindo para a ocorrência de precipitação nessas regiões (Marengo et al. 2004, Marengo, 2004, 2005 e 2006; Vera et al., 2006; Correia et al., 2007; Satyamurty et al., 2013). Nesse sentido, Arraut e Satyamurty (2009) mostraram que a atividade convectiva sobre o sul do Brasil e norte da Argentina é influenciada pelo transporte de umidade através da fronteira sul da bacia amazônica, realizado pelos Jatos de Baixos Níveis (JBNs) a leste dos Andes.

O conceito de reciclagem de precipitação refere-se ao mecanismo de retroalimentação "feedback" entre a superfície e a atmosfera onde a evapotranspiração local contribui, significativamente, na precipitação total sobre uma região (Figura 1). Em outras palavras, a reciclagem de precipitação pode ser definida como a quantidade de água que evapotranspirada da superfície terrestre em uma determinada região retorna na forma de precipitação sobre a mesma região (Brubaker et al., 1993; Eltahir e Bras, 1994; Trenberth, 1999).

Com base na interpretação de dados observacionais, de reanálises e de modelos numéricos de diferentes centros meteorológicos, diversos estudos foram realizados com o objetivo de quantificar e descrever a distribuição da reciclagem de precipitação na bacia amazônica: Molion (1975) - 56\%; Marques et al. (1977) - 50\%; Brubaker et al. (1993) - 24\%; Eltahir e Bras (1994) - 25-35\%; Trenberth (1999) - 34\%; Costa e Foley (1999) - 20\%; Nóbrega et al. (2005) - 24\%; Silva (2009) - 27\%; Van der Ent et al. (2010) - 28\%; e Satyamurty et al. (2013) - 30\%. Os resultados desses estudos, apesar de apresentarem diferenças quantitativas, demonstram que a quantificação desse mecanismo (reciclagem de precipitação) é um forte indicador da importância dos processos de superfície e do clima no ciclo hidrológico, assim como da sensibilidade climática relacionada às alterações nesses processos.

Este artigo traz uma perspectiva histórica da evolução do conhecimento sobre a reciclagem de precipitação, abordando os mecanismos de retroalimentação envolvidos nesse processo, e fornece uma visão crítica do estado da arte atual. São retratadas as características do clima da Amazônia no que concerne às principais fontes de umidade para a precipitação regional, assim como o transporte de vapor d'água sobre a América do Sul. Uma revisão dos estudos observacionais e de modelagem numérica com o objetivo de quantificar e avaliar a reciclagem de precipitação na Amazônia e em outras regiões do planeta é apresentada.

\section{FONTES DE UMIDADE PARA A AMAZÔNIA E O TRANSPORTE DE VAPOR D'ÁGUA SOBRE A AMÉRICA DO SUL}

A grande maioria dos estudos sobre reciclagem de precipitação tem demonstrado que este mecanismo é fortemente influenciado pela precipitação total, pela evapotranspiração da superfície e pelo transporte de vapor d'água sobre a região.

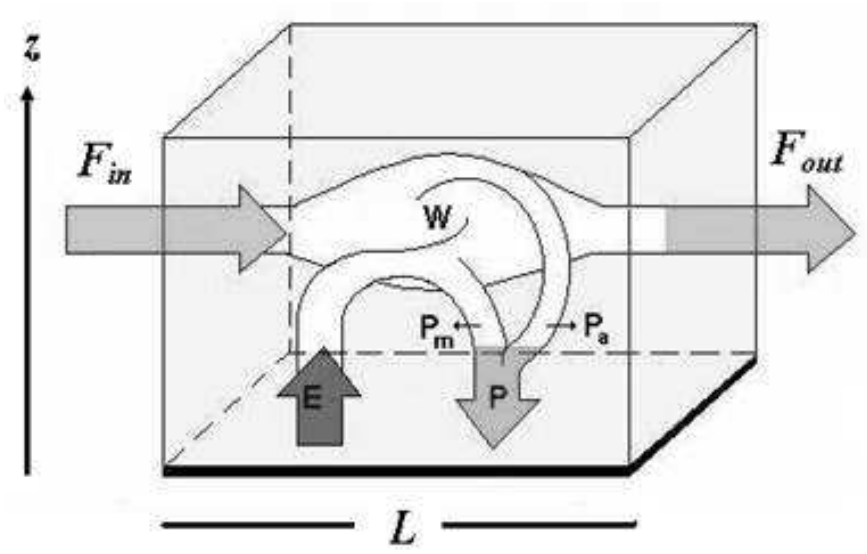

Figura 1 - Modelo conceitual de reciclagem de precipitação. Os termos $\mathrm{Pm}$ e $\mathrm{Pa}$ referem-se às taxas de precipitação provenientes da evapotranspiração e do vapor d'água advectados para a região, respectivamente; Fine Fout são os fluxos de vapor d'água que entra e sai da região considerada, respectivamente; E é a taxa de evapotranspiração e W é o armazenamento de água na atmosfera (água precipitável). Fonte: Adaptado de Brubaker et al. (1993). 
O fluxo de umidade do Atlântico Equatorial associado com os ventos alísios é a principal fonte de umidade para a Amazônia (Costa e Foley, 1999; Arraut e Satyamurty, 2009; Arraut et al., 2012; Satyamurty et al., 2013). Avaliando o transporte de vapor d'água e a reciclagem de precipitação na Amazônia utilizando dados de reanálises do National Center for Environmental Prediction/National Center for Atmospheric Research - NCEP/NCAR (Kalnay et al. 1996), Satyamurty et al. (2013) mostraram que: as fontes de umidade para a bacia amazônica estão localizadas no Oceano Atlântico Tropical Norte e Sul; o transporte de umidade que alimenta a bacia ocorre de leste para oeste durante todas as estações do ano; e a reciclagem de precipitação, por meio da evapotranspiração, é estimada em cerca de $33 \%$ no período chuvoso e apresenta valores menores na estação seca.

Drumond et al. (2014) utilizaram um modelo Lagrangiano (FLEXPART) e as reanálises ERA-Interim no período de 19792012 para investigar o papel da umidade da bacia amazônica no balanço hidrológico regional ao longo do ano. Os resultados obtidos indicam que o Atlântico Tropical é a principal fonte de umidade para a Amazônia. O Atlântico Tropical Norte contribui principalmente durante o verão austral, enquanto que a contribuição do Atlântico Tropical Sul prevalece no restante do ano. Durante eventos de El Niño, a contribuição do Atlântico Norte aumenta superficialmente entre junho-janeiro, ao passo que a contribuição do Atlântico Sul é maior no outono do ano seguinte.

Drumond et al. (2008) investigaram as principais fontes de umidade para o Brasil Central e a bacia do Prata num período médio de 5 anos (2000-2004), utilizando um método Lagrangiano que identifica as contribuições de umidade no balanço de água de uma região. Os resultados encontrados revelam a importância do Atlântico Tropical Sul, enquanto fonte de umidade para o Brasil Central, assim como, da reciclagem de precipitação para a bacia do Prata, sobretudo durante o verão austral. Ademais, o Atlântico Tropical Norte é também considerado uma fonte adicional de umidade para ambas as regiões. Doyle e Barros (2002) verificaram que a circulação associada à parte oeste da Alta Subtropical do Atlântico Sul transporta vapor d'água do Oceano Atlântico Sul para a América do Sul Subtropical.

O papel climatológico do Oceano Atlântico Norte Subtropical como fonte de umidade para a Amazônia foi discutido por Gimeno et al. (2012 e 2013), que avaliaram a influência das regiões oceânicas na precipitação continental. De acordo com os autores, o Oceano Atlântico Norte Subtropical fornece umidade para a precipitação em uma grande área continental, que se estende do México até partes da Eurásia e, até mesmo, para o continente sul-americano durante o inverno boreal.

A bacia amazônica também se comporta como fonte de vapor d'água para outras regiões, fornecendo umidade predominantemente para o sudeste da América do Sul, região Central e Sudeste do Brasil, e bacia do Prata, e principalmente nos meses de primavera e verão (Marengo, 2005; Drumond et al., 2008; Arraut e Satyamurty, 2009). A umidade fornecida a partir da evapotranspiração da Amazônia é transportada pelos ventos predominantes, e a precipitação decorrente da evapotranspiração aumenta de nordeste para sudoeste na bacia (Eltahir e Bras, 1994). Parte da umidade é interceptada pela Cordilheira dos Andes e transportada através dos JBNs, a leste da cadeia de montanhas, para a bacia do Prata, sendo que $70 \%$ da precipitação nesta região é de origem terrestre; isto significa que, a evapotranspiração com origem na Amazônia tem uma contribuição significativa sobre os recursos hídricos na bacia do Prata (Van der Ent et al., 2010). Ademais, segundo Drumond et al. (2014), o transporte de umidade da Amazônia em direção ao sudeste da América do Sul aumenta durante anos cujo fenômeno El Niño é configurado.

Os JBNs ocorrem com frequência em muitas partes do mundo. Estes ventos de máxima velocidade nos baixos níveis da atmosfera são importantes no que concerne aos fluxos verticais e horizontais de temperatura e umidade, e estão associados com o desenvolvimento e a evolução da convecção profunda. Uma vez que a convecção profunda é ativada, uma quantidade significativa de nebulosidade é produzida, sobretudo nos níveis superiores, e isto é responsável por parte da precipitação sobre a América do Sul durante o verão. A relação entre JBNs e convecção profunda sugere que os JBNs exercem um importante papel na manutenção do clima regional (Stensrud, 1996).

Marengo et al. (2004) desenvolveram uma climatologia do JBN da América do Sul (Figura 2), a leste dos Andes, utilizando os campos de umidade e circulação provenientes das reanálises do NCEP-NCAR no período de 1950-2000 e observações de ar superior realizadas sobre a Bolívia e o Paraguai desde 1998. Os campos de circulação nos níveis alto e baixo da atmosfera foram derivados das médias sazonais e os compostos do JBN durante as estações de verão e inverno. No que concerne às características da circulação regional, durante o verão os compostos do JBN mostram o aumento no transporte de umidade meridional em baixos níveis proveniente da América do Sul Equatorial, bem como, um trem de ondas em altos níveis oriundo da parte oeste do Oceano Pacífico propagando-se para o continente sul americano. A intensificação do JBN no verão austral associa-se ao estabelecimento de uma crista em altos níveis no sul do Brasil e um cavado sobre grande parte da Argentina. As anomalias de circulação nos níveis superior e inferior da atmosfera sugerem que a intensificação do JBN afeta a Zona de Convergência do Atlântico Sul (ZCAS), intensificando-a e, posteriormente, a penetração de frentes frias produz chuvas intensas na região de saída do jato, contribuindo para a formação dos Complexos Convectivos de Mesoescala (CCM). 
Com relação à variabilidade temporal, o JBN da América do Sul parece ocorrer durante todo o ano, transportando massas de ar úmida tropical da Amazônia para o centro-sul do Brasil e norte da Argentina, sobretudo no verão, e conduzindo massa de ar tropical marítima da alta subtropical do Atlântico mais frequentemente no inverno. No verão, os JBNs são observados principalmente ao norte de $20^{\circ} \mathrm{S}$, aproximadamente, enquanto que ao sul eles parecem ocorrer durante o ano todo. Em escalas de tempo interanual, embora exista uma fraca tendência para fortes e mais frequentes episódios de JBN durante o verão em anos com águas superficiais aquecidas anomalamente no Pacífico Tropical, não é possível afirmar que há uma relação consistente entre a ocorrência de eventos de El Niño e o número e/ou intensidade de episódios de JBN (Marengo et al., 2004).

Grande parte do vapor d'água, transportado meridionalmente através das latitudes médias, ocorre por meio de corredores estreitos denominados Rios Atmosféricos (RAs) (Zhu e Newell, 1998). Em outras palavras, o conceito de RAs remete-se às principais vias do fluxo de umidade na atmosfera. Ao contrário dos rios de superfície, os rios atmosféricos ganham (perdem) água por meio da evaporação (precipitação) (Arraut et al., 2012). Conforme salienta Gimeno et al. (2014), os RAs são caracterizados pelo alto conteúdo de vapor d'água e ventos fortes em baixos níveis (um JBN), e formam uma parte do extenso cinturão de correntes quentes dos ciclones extratropicais que desempenham um importante papel no transporte de calor sensível e latente em direção aos polos, para equilibrar a contribuição de outros componentes do ciclone que transportam relativamente ar frio e seco para o equador.
Arraut et al. (2012) realizaram um estudo observacional do transporte de umidade em larga escala sobre a América do Sul e sua relação com a precipitação subtropical. De acordo com os autores, os ventos de leste (alísios) sobre a Amazônia juntamente com o fluxo norte/noroeste para as regiões subtropicais, a leste dos Andes, constituem os RAs da América do Sul (Figura 3). Outrossim, definido pelos autores, os lagos atmosféricos são os setores da via de umidade onde o fluxo desacelera e se alarga, devido à difluência, tornando-se mais profundo e com maior água precipitável. Este é o caso sobre a Amazônia, região a jusante da confluência dos ventos alísios. A descarga do RA nos subtrópicos é comparável à do Rio Amazonas. As variações na quantidade de umidade proveniente da Amazônia tem um efeito importante na variabilidade da descarga. No entanto, as correlações entre o fluxo oriundo da Amazônia e a precipitação subtropical não são fortes. O transporte de umidade das fontes oceânicas para os continentes estabelece a conexão entre a evaporação oceânica e a precipitação continental. Um estudo detalhado deste transporte pode fornecer uma melhor compreensão, tanto das mudanças observadas, quanto de alguma evidência física para sustentar os resultados de projeções do clima futuro (Gimeno et al., 2012). Cenários de mudanças climáticas sugerem que a alta sensibilidade da pressão de saturação do vapor d'água à temperatura resultará em aumentos na evaporação e, portanto, na precipitação, conduzindo a intensificação do ciclo hidrológico (Held e Soden, 2006). Nesse sentido, Gimeno et al. (2013) investigaram duas questões chaves referentes ao ramo atmosférico do ciclo hidrológico que, ainda, permanecem uma

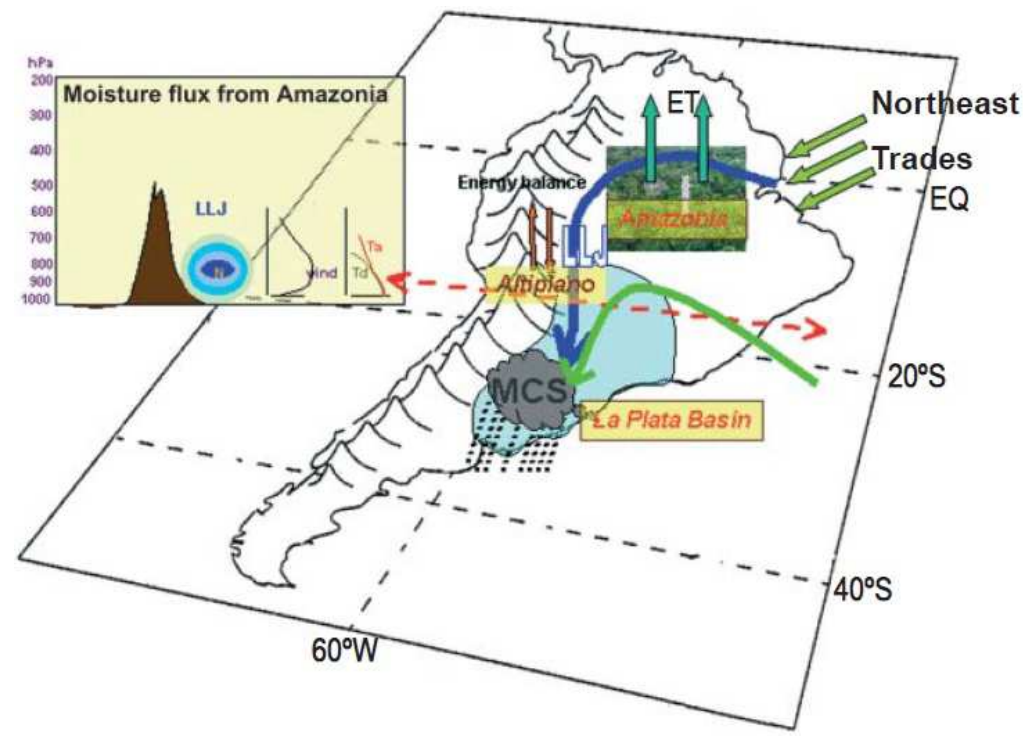

Figura 2 - Modelo conceitual do jato de baixos níveis (JBN), a leste dos Andes, que transporta umidade da Amazônia (flecha azul) e do oceano Atlântico subtropical (flecha verde).

Fonte: Marengo et al. (2004). 
incógnita: (1) de que maneira as mudanças climáticas afetam o transporte de umidade? e, em especial, (2) de que modo as possíveis alterações na intensidade e localização das fontes poderiam afetar a distribuição da precipitação continental num clima em mudança?. Os autores utilizaram um conjunto de simulações de multi-modelos (multimodel ensemble) que permitiu delimitar as regiões oceânicas onde as mudanças climáticas provavelmente conduzirão o aumento na evaporação (E) menos precipitação (P). Um modelo Lagrangiano foi utilizado para identificar quais regiões continentais serão afetadas pelas mudanças na precipitação $(\mathrm{E}-\mathrm{P}<0)$ proveniente de cada fonte de umidade oceânica. De acordo com os resultados, durante o inverno boreal grande parte da Europa, Ásia, Oriente Médio, América do Sul e África Meridional é afetada, porém a América do Norte surge como a região continental mais impactada. No inverno austral, as mudanças mais pronunciadas ocorrem, sobretudo, na América Central e do Norte.

Outra importante questão científica que necessita de melhor entendimento é o papel desempenhado pela Oscilação do Atlântico Norte e pelo El Niño-Oscilação Sul na variabilidade das regiões fontes de umidade, bem como uma avaliação detalhada da umidade transportada pelos JBNs e os RAs.

\section{MECANISMOS DE RETROALIMENTAÇÃO DO PROCESSO DE RECICLAGEM DE PRECIPITAÇÃO}

A umidade que origina a precipitação sobre regiões continentais é proveniente de duas fontes: (i) advecção de vapor d'água oriundo de outras regiões por meio de movimentos de massas de ar e (ii) o vapor d'água local por meio da evapotranspiração da superfície da região.
A reciclagem de precipitação é definida como a água que evapora da superfície continental dentro de um volume de controle e precipita no mesmo volume (Brubaker et al.,1993), ou como o índice da razão da precipitação reciclada em relação à precipitação total, e tem por característica uma relação não linear entre a evapotranspiração, o transporte de umidade e a precipitação total em uma região. O transporte de umidade para a região depende da dinâmica atmosférica e das fontes de origem da umidade. A evapotranspiração, por sua vez, depende da disponibilidade de umidade na área ou abaixo da superfície (zona insaturada), que é evaporada diretamente ou através da transpiração da vegetação. Consequentemente, qualquer alteração no uso e cobertura da terra e no clima que modifiquem esses processos pode afetar a quantidade de precipitação sobre a região, assim como a reciclagem.

Por meio de estudos observacionais e de experimentos numéricos sabe-se que a evapotranspiração da superfície tem dois efeitos:

1. A evapotranspiração aumenta a umidade atmosférica, o que favorece mais precipitação. Dados observacionais sobre a Amazônia e outras regiões (Eltahir e Bras, 1994; Trenberth, 1999) mostram uma contribuição significativa da evapotranspiração local para a umidade atmosférica. A importância relativa depende da quantidade de umidade advectada para a região, isto é, a evapotranspiração terá efeito pronunciado quando a umidade advectada for pequena. Bosilovich e Schubert (2001) calcularam uma taxa de reciclagem de precipitação $20 \%$ menor sobre a região central dos Estados Unidos durante a inundação de 1993, quando uma grande quantidade de umidade foi advectada para a região. Esta taxa é maior que $60 \%$

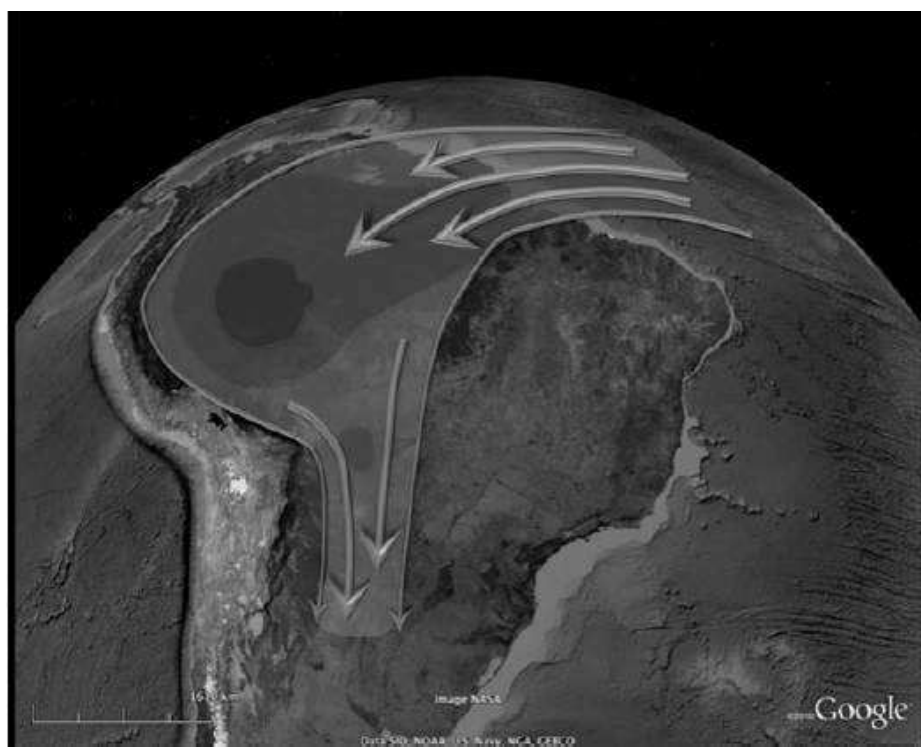

Figura 3 - Modelo conceitual do sistema de lagos e rios atmosféricos (RAs) sobre a América do Sul na estação chuvosa. Fonte: Arraut et al. (2012). 
durante o mesmo mês no ano seco de 1988, associada com menores quantidades de umidade advectada;

2. A evapotranspiração altera a termodinâmica da coluna vertical de água, favorecendo precipitações futuras. Maior evapotranspiração (associada com solos úmidos) reduz tanto o albedo da superfície, quanto a razão de Bowen (Brutsaert, 1982). Isto resulta em maior saldo de radiação à superfície e aumento na transferência de calor para a atmosfera, o que implica em aumento na energia estática úmida da camada limite. A energia estática úmida desempenha um importante papel na dinâmica das tempestades convectivas locais, o que fortalece a circulação de monção em grande escala (Schar et al., 1999; Eltahir, 1998).

Gimeno et al. (2012) identificaram as principais fontes de umidade atmosférica, tanto oceânicas quanto terrestres, em escala global. Os autores avaliaram como as áreas continentais são influenciadas pela água de diferentes regiões fontes de umidade. Segundo os autores, algumas porções continentais somente recebem umidade da evaporação que ocorre no mesmo hemisfério (por exemplo, a Europa Setentrional e a América do Norte Oriental); enquanto que outras regiões são abastecidas de umidade de ambos os hemisférios, com grandes variações sazonais, tais como a América do Sul Setentrional, incluindo a bacia amazônica.

Drumond et al. (2011) investigaram o papel das águas quentes do Hemisfério Ocidental Tropical (Tropical Western Hemisphere Warm Pool - WHWP) no fornecimento de umidade para a atmosfera no decorrer do ciclo anual a fim de identificar as regiões que podem ser afetadas pela precipitação cuja origem encontra-se nesta fonte. Utilizando o modelo Lagrangiano FLEXPART e as condições médias mensais no período de 2000-2004, os autores mostraram a contribuição da WHWP para os regimes de precipitação sobre o leste da América do Norte, Atlântico Norte e na Zona de Convergência Intertropical (ZCIT), considerada o mais importante sistema meteorológico de chuva para a região tropical, sobretudo na Amazônia (Marengo e Nobre, 2009).

Embora a maior parte da umidade necessária para gerar as chuvas na Amazônia seja proveniente de fora da região, a contribuição da evapotranspiração local para a precipitação sobre a bacia representa uma porção significativa do balanço de água regional e desempenha um importante papel no ciclo hidrológico amazônico, influenciando os padrões espaciais de umidade do solo, a produtividade e a ocorrência de eventos extremos, tais como enchentes e secas (Correia et al., 2007; Rocha et al., 2009; Satyamurty et al., 2013). O papel da vegetação no abastecimento do transporte de umidade sobre a Amazônia foi discutido por Spracklen et al. (2012). Os autores observaram que a massa de ar que passa sobre áreas de floresta densa produz, pelo menos, o dobro de chuva em comparação ao ar que passa sobre superfícies com pouca vegetação.

Angelini et al. (2011) quantificaram a extensão do acoplamento entre a vegetação e a atmosfera sobrejacente utilizando dados climatológicos referentes à emissividade, temperatura do ponto de orvalho, e os registros históricos de precipitação e cobertura florestal, dentre outros. A partir da análise isotópica da precipitação, os autores encontraram que a chuva na Amazônia ocorre, a princípio, devido a sistemas meteorológicos de grande escala, não sendo acionada diretamente pela evapotranspiração local. De acordo com o estudo, alterações na cobertura vegetal influenciam a temperatura e o conteúdo de umidade à superfície, assim como a camada limite atmosférica, mas não se refletem em mudanças na precipitação; o que significa, segundo os autores, que as mudanças na precipitação sobre grandes áreas continentais são um produto de processos complexos apenas parcialmente influenciados, mas não controlados, pelas fontes de água locais e/ou a vegetação.

As transições de fase da água na atmosfera desempenham um importante papel no sistema climático terrestre, mas seu impacto direto na dinâmica atmosférica necessita de grande atenção. Nesse sentido, Makarieva et al. (2013) avaliaram como a condensação influencia a pressão atmosférica através da remoção da massa da água a partir da fase gasosa com um balanço simultâneo da liberação do calor latente. Os autores mostraram que a condensação está associada com uma diminuição da pressão do ar na baixa atmosfera. Esta diminuição ocorre até certa altura, que varia de 3 a $4 \mathrm{~km}$ para temperaturas de superfície de $10^{\circ}$ a $30^{\circ} \mathrm{C}$. Makarieva et al. (2013) estimaram as diferenças de pressão horizontal associadas com a condensação do vapor d'água e encontraram que estes são comparáveis em magnitude com as diferenças de pressão conduzidas pelos padrões de circulação observados. O vapor d'água fornecido para a atmosfera através da evaporação representa um estoque de energia potencial disponível para acelerar o ar e, assim, conduzir ventos. Os resultados encontrados sugerem ainda que a potência média global em que esta energia potencial é liberada pela condensação é de, aproximadamente, $1 \%$ da energia solar global, isto é semelhante à energia dissipativa estacionária da circulação geral da atmosfera.

\section{RECICLAGEM DE PRECIPITAÇÃO: ESTUDOS OBSERVACIONAIS E DE MODELAGEM NUMÉRICA}

Vários estudos observacionais e de modelagem numérica têm sido realizados com o objetivo de avaliar a reciclagem de precipitação em diferentes regiões do planeta, como os de Budyko (1974), Molion (1975), Marques et al. (1977), Brubaker 
et al. (1993), Eltahir e Bras (1994 e 1996), Savenije (1995), Trenberth (1999), Costa e Foley (1999), Bosilovich e Schubert (2001), Nóbrega et al. (2005), Silva (2009), Van der Ent et al. (2010) e Satyamurty et al. (2013).

Diversos trabalhos realizados anteriormente estimaram diferentes taxas de reciclagem de precipitação sobre uma mesma região. Isto ocorre, dentre outros fatores, devido ao método utilizado para quantificar a reciclagem de precipitação e a fonte de dados utilizados, e também a estação do ano considerada no estudo. Bosilovich e Schubert (2001), utilizando as reanálises do National Aeronautics and Space Administration Goddard Earth Observing System (GEOS-1) e dois métodos distintos baseados no balanço de umidade, calcularam em dois diferentes episódios de verão a taxa de reciclagem de precipitação sobre a região central dos Estados Unidos. Os autores encontraram uma taxa de reciclagem de $25 \%$ e $36 \%$ a partir dos métodos descritos por Brubaker et al. (1993) e Eltahir e Bras (1996), respectivamente.

A Tabela 1 apresenta uma comparação entre alguns dos resultados encontrados na literatura referentes à reciclagem de precipitação anual em diferentes regiões do planeta. A localização aproximada das regiões pode ser consultada na Figura 4.
Budyko (1974) desenvolveu um modelo unidimensional para estimar a contribuição da evapotranspiração local e umidade advectada na precipitação sobre grandes regiões. $\mathrm{O}$ autor definiu $\beta$ como a razão entre a precipitação total $\mathrm{e}$ a precipitação que é originada devido à umidade advectada. Calculando $\beta$ para a Eurásia, o autor estimou que a contribuição local para a precipitação média anual sobre a região foi de apenas $11 \%$.

Os estudos sobre o balanço de umidade na região amazônica foram inicialmente realizados com observações de precipitação, vazões dos rios e dados de algumas poucas estações de radiossondagem. Esses estudos mostraram que, em média, 50\% da precipitação é reciclada e volta à atmosfera por meio da evapotranspiração (Molion, 1975; Marques et al., 1977). Outrossim, as pesquisas pioneiras consideraram que toda a evapotranspiração na bacia era transformada em precipitação na própria região.

No entanto, com base no estudo do balanço dos isótopos de $\mathrm{O}^{18}$ do vapor d'água que entra na região e nas águas do Rio Amazonas, Salati et al. (1979) estimaram que grande parte do vapor que entra na região pelos ventos alísios é transportado para fora da bacia e contribui para a geração de precipitação em outras regiões. De acordo com os autores, esse fluxo de umidade

Tabela 1 - Média anual da reciclagem de precipitação sobre diferentes regiões.

\begin{tabular}{|c|c|c|c|c|c|}
\hline Bacia & Amazônia & Mississipi & África Ocidental & Eurásia & Método e dados \\
\hline Budyko (1974) & & & & $11 \%$ & $\begin{array}{l}\text { Modelo unidimensional de Budyko e dados observados } \\
\text { de várias fontes. }\end{array}$ \\
\hline $\begin{array}{l}\text { Molion (1975) e } \\
\text { Marques et al. (1977) }\end{array}$ & $\begin{array}{l}56 \% \\
50 \%\end{array}$ & & & & $\begin{array}{l}\text { Observações de precipitação, vazões dos rios e dados de } \\
\text { radiossondagem. }\end{array}$ \\
\hline Brubaker et al. (1993) & $24 \%$ & $24 \%$ & $31 \%$ & $11 \%$ & $\begin{array}{l}\text { Modelo de Budyko reformulado em duas dimensões e } \\
\text { dados observados. }\end{array}$ \\
\hline Eltahir e Bras (1994) & $\begin{array}{l}25 \% \\
35 \%\end{array}$ & & & & $\begin{array}{l}\text { Modelo numérico bi-dimensional e duas fontes de dados: } \\
\operatorname{ECMWF}^{1}(25 \%) \text { e } \operatorname{GFDL}^{2}(35 \%) \text {. }\end{array}$ \\
\hline Trenberth (1999) & $34 \%$ & $21 \%$ & & & $\begin{array}{l}\text { Modelo de Brubaker et al. (1993) com base na escala de } \\
\text { comprimento } L \text {. Na Amazônia } L \text { é } 2750 \mathrm{~km} \mathrm{e} \mathrm{no} \\
\text { Mississipi } L \text { é } 1800 \mathrm{~km} \text {. Dados do CMAP }{ }^{3} \mathrm{NVAP}^{4} \text { e } \\
\text { NCEP }^{5} \text {. }\end{array}$ \\
\hline Silva (2009) & $27 \%$ & & & & $\begin{array}{l}\text { Modelo de Brubaker et al. (1993) e as reanálises do } \\
\text { NCEP/NCAR (1979-2007). }\end{array}$ \\
\hline Van der Ent et al. (2010) & $28 \%$ & $27 \%$ & $45 \%$ & $28 \%$ & Reanálises do ECMWF (ERA-Interim, 1999-2008). \\
\hline Satyamurty et al. (2013) & $30 \%$ & & & & Reanálises do NCEP/NCAR (1978-2010). \\
\hline
\end{tabular}

${ }^{\mathrm{E}}$ European Centre for Medium-Range Weather Forecasts.

${ }^{2}$ Geophysical Fluid Dynamics Laboratory.

${ }^{3}$ Climate Prediction Center Merged Analysis of Precipitation.

${ }^{4}$ NASA Water Vapor Project.

${ }^{5}$ National Centers for Environmental Prediction. 


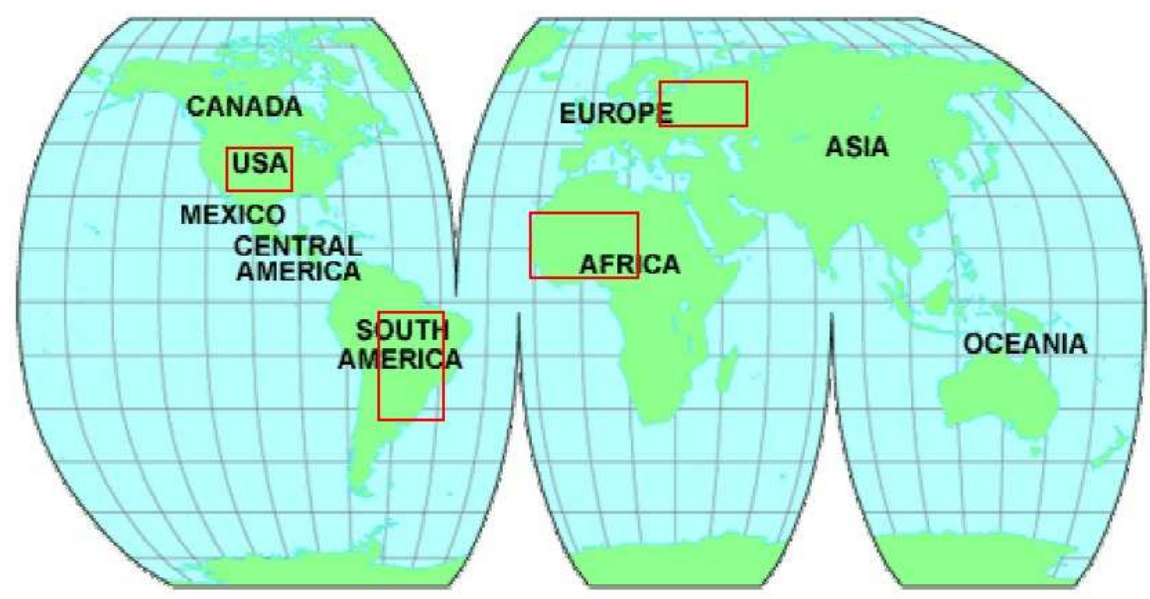

Figura 4 - Regiões onde a reciclagem de precipitação, apresentada na Tabela 1, foi calculada. Fonte: Mohamed e Savenije (2002).

é da ordem de 3 a $5 \times 10^{12} \mathrm{~m}^{3}$ ano ${ }^{-1}$ e parte desse vapor d'água dirige-se para a região Centro-Sul do continente sul-americano.

Brubaker et al. (1993) adaptaram o modelo desenvolvido por Budiko (1974) em duas dimensões, com fluxos de umidade entrando e saindo em um volume de controle. Utilizando dez anos de dados observados de vento e umidade do Geophysical Fluid Dynamics Laboratory (GFDL) - National Oceanic and Atmospheric Administration (NOAA), os autores determinaram a convergência de vapor d'água atmosférico e a fração da precipitação que tem origem local, sobre quatro regiões continentais: Eurásia, África, América do Norte e Amazônia. De acordo com os resultados obtidos, os autores verificaram que a contribuição da evapotranspiração para a precipitação local varia sazonal e localmente. A reciclagem média anual determinada para as quatro regiões foram: Eurásia - 11\%; América do Norte - 24\% e África Ocidental- 31\%. Na Amazônia, os valores máximo (32\%) e mínimo (14\%) foram estimados nos meses de dezembro e junho, respectivamente.

Eltahir e Bras (1994) desenvolveram um modelo numérico bi-dimensional e utilizaram dados de reanálises (ECMWF e GFDL) para quantificar a reciclagem de precipitação na bacia amazônica. Os resultados encontrados revelaram uma reciclagem média anual da ordem de $25 \%$ e $35 \%$ de acordo com os dados do ECMWF e do GFDL, respectivamente. A distribuição espacial da reciclagem de precipitação apresentou diferenças significativas. A razão máxima de reciclagem foi identificada no setor sudoeste da bacia, com índices superiores a $50 \%$.

Savenije (1995) utilizou um modelo unidimensional para calcular a reciclagem de precipitação em Sahel (África Ocidental) com base em dados observacionais de chuva e escoamento superficial no período de 1950-1990. Segundo o autor, a evapotranspiração é o mais importante mecanismo de retroalimentação "feedback", que sustenta as chuvas em bacias continentais, especialmente em regiões semiáridas. A reciclagem no Sahel é responsável por mais de $90 \%$ da precipitação na estação chuvosa; contudo, o valor encontrado é considerado superestimado, uma vez que a umidade no modelo proposto por Savenije (1995) não deixa a região através da atmosfera, mas apenas pelo escoamento superficial "runoff".

Trenberth (1999) utilizou o modelo proposto por Brubaker et al. (1993) e os dados do CMAP, NVAP e reanálises do NCEP/NCAR, no período de 1979-1995, para avaliar a distribuição espacial e sazonais na reciclagem de precipitação em escala global. Os resultados encontrados mostram que o valor da reciclagem de precipitação depende da escala de comprimento $L$ considerada. Na Amazônia, a forte advecção de umidade domina o fornecimento de vapor d'água em grande parte da região, porém, o papel da evapotranspiração local é mais importante sobre o setor sul da bacia. Considerando o ciclo anual, cerca de $34 \%$ da precipitação é reciclada localmente. Entretanto, para a bacia do Mississipi, a reciclagem de precipitação estimada é da ordem de $21 \%$.

Também utilizando as reanálises do NCEP/NCAR, a reciclagem de precipitação na Amazônia foi estimada por Costa e Foley (1999) - 20\%; Nóbrega et al. (2005) - 24\%; Silva (2009) $-27 \%$ e Satyamurty et al. (2013) - 30\%. Um resumo desses estudos sugere que: (a) os fluxos de vapor d'água do Atlântico Equatorial associados aos ventos alísios são as principais fontes de umidade para a bacia amazônica; (b) admitindo-se que o Atlântico Norte seja a única fonte de umidade, é impossível explicar o padrão das chuvas na Amazônia, o que ressalta o papel da floresta na reciclagem de precipitação; e (c) a Amazônia é a principal fonte de umidade para o Brasil Central no período de setembro a fevereiro (Marengo e Nobre, 2009).

Costa e Foley (1999) analisaram a variabilidade dos componentes do balanço de umidade na bacia para o período de 1976-1996. Os autores observaram que existe uma tendência 
de diminuição no transporte de vapor d'água, tanto o que entra, quanto o que sai, sobre a Amazônia. Essa tendência está associada com o "enfraquecimento" dos ventos alísios de sudeste, assim como do gradiente de pressão leste-oeste, e com o aquecimento da temperatura da superfície do mar (TSM) no Atlântico equatorial sul. Enquanto o transporte atmosférico de vapor d'água através da Amazônia reduziu, a reciclagem de precipitação no interior da bacia aumentou.

Nóbrega et al. (2005) analisaram os campos do fluxo de vapor d'água, evapotranspiração e precipitação no período entre 1978-1998 para investigar a variabilidade sazonal e interanual da reciclagem de precipitação sobre a América do Sul. Os resultados encontrados indicaram valores de reciclagem relativamente pequenos sobre a Amazônia e o Nordeste do Brasil, e maiores na parte central da América do Sul, com núcleos de até $50 \%$ durante o verão. De acordo com os autores, os aspectos climatológicos da reciclagem de precipitação sobre a América do Sul mostram que a contribuição advectiva é mais importante para a precipitação sobre a Amazônia e o Nordeste do Brasil, ao passo que na região Centro-Sul a contribuição local tem importante papel na precipitação. A reciclagem média anual verificada sobre a bacia amazônica foi da ordem de $24 \%$, com valor mínimo (21\%) no bimestre junho-julho e máximo (27\%) no mês de novembro.

Silva (2009) avaliou a reciclagem e a precipitação de origem externa em seis regiões distintas da América do Sul para o período de 1979-2007, conforme o modelo desenvolvido por Brubaker et al. (1993). Os campos sazonais da precipitação de origem externa sobre a porção norte da América do Sul indicam contribuição dominante da umidade de leste, principalmente durante o inverno. Por outro lado, a maior parte da precipitação que ocorre sobre o Centro-Oeste e Sudeste do Brasil deve-se à umidade proveniente do leste e do norte. Sobre o sul da América do Sul, a maior contribuição para a precipitação é proveniente da umidade vinda do oeste. Na Amazônia setentrional (central), verificou-se que $77 \%$ (73\%) da precipitação é proveniente de umidade externa e $23 \%$ (27\%) de origem local; na região Centro-Oeste, $36 \%$ da precipitação é de origem externa e $64 \%$ é gerada localmente; no Sudeste do Brasil, 30\% da precipitação é de origem externa e cerca de $70 \%$ é local; na bacia do Prata, aproximadamente $55 \%$ da precipitação é de origem externa e $45 \%$ é gerada localmente.

Van der Ent et al. (2010) demonstraram o quão importante é o papel da circulação geral da atmosfera, topografia e uso da terra nos padrões de reciclagem de precipitação sobre os continentes e na distribuição mundial dos recursos hídricos. Os autores utilizaram os dados de reanálises do ECMWF (ERA-Interim, no período de 1998-2008) para quantificar os índices globais de reciclagem. De acordo com o estudo, em média, $40 \%$ da precipitação sobre os continentes tem origem na evapotranspiração da superfície terrestre; além disso, 57\% de toda a evapotranspiração da superfície retornam como precipitação sobre os continentes. Os valores da reciclagem de precipitação estimada para o continente sul americano e, especificamente, na Amazônia foram de 36\% e 28\%, respectivamente.

Viana et al. (2010) utilizaram o modelo regional BRAMS (Brazilian Regional Atmospheric Modeling System) para avaliar os efeitos sobre a reciclagem de precipitação decorrentes do desflorestamento de grande escala na bacia amazônica. As condições iniciais e de contorno foram fornecidas pelo Modelo de Circulação Geral da Atmosfera (MCGA - CPTEC/INPE). Para estimar a reciclagem de precipitação os autores se basearam no método desenvolvido por Brubaker et al. (1993). Os resultados revelaram uma heterogeneidade na reciclagem de precipitação, com valores mais intensos no centro-sul da bacia, principalmente no período chuvoso. Na estação seca (chuvosa), a reciclagem de precipitação foi da ordem de $14,3 \%$ (25\%); sendo que, a redução na evapotranspiração e o aumento no transporte de umidade contribuíram, significativamente, para a diminuição da reciclagem no período de estiagem.

Com base nos resultados dos estudos discutidos, estima-se que a reciclagem de precipitação na bacia amazônica é da ordem de $20-35 \%$. Tanto o desflorestamento, quanto as mudanças do clima global, devido ao aumento das emissões antropogênicas dos gases de efeito estufa, podem afetar o funcionamento dos ecossistemas amazônicos, reduzindo sua capacidade de capturar o carbono da atmosfera, aumentando a temperatura à superfície, reduzindo a umidade do solo, modificando o ciclo hidrológico regional e, conseqüentemente, a reciclagem (Marengo et al., 2011). Embora os estudos sobre reciclagem de precipitação tenham produzido novos conhecimentos acerca da interação entre os processos de superfície e o ciclo hidrológico, os efeitos das mudanças climáticas globais nesse mecanismo ainda não estão completamente compreendidos.

\section{CONSIDERAÇÕES FINAIS}

O presente trabalho apresentou uma perspectiva histórica da evolução do conhecimento e uma visão crítica do estado da arte atual sobre a reciclagem de precipitação, abordando os mecanismos de retroalimentação envolvidos nesse processo. Foram retratadas as características do clima da Amazônia no que diz respeito às principais fontes de umidade para a precipitação na região, bem como o transporte de vapor d'água sobre o continente sul americano. Uma revisão dos estudos observacionais e de modelagem numérica com o objetivo de quantificar e avaliar a reciclagem de precipitação na Amazônia e em outras regiões do planeta foi apresentada. 
O transporte de umidade das fontes oceânicas para os continentes estabelece a conexão entre a evaporação oceânica e a precipitação continental. Nesse sentido, o fluxo de umidade do Atlântico Equatorial associado com os ventos alísios é a principal fonte de umidade para a Amazônia. O transporte de vapor d'água que alimenta a bacia ocorre de leste para oeste durante todo o ano. A Amazônia também se configura uma importante fonte de umidade para o sudeste da América do Sul, região Central e Sudeste do Brasil, e bacia do Prata, sobretudo durante a primavera e o verão. $O$ vapor d'água fornecido a partir da evapotranspiração da floresta é transportado pelos ventos predominantes, e a precipitação decorrente da evapotranspiração aumenta de nordeste para sudoeste na bacia. Parte da umidade é interceptada pelos Andes e transportada através dos JBNs para a bacia do Prata, no qual $70 \%$ da precipitação nesta região é de origem terrestre.

A quantificação do mecanismo de reciclagem é um forte indicador da importância dos processos de superfície e do clima no ciclo hidrológico, assim como, da sensibilidade climática relacionada às alterações nesses processos. Os aspectos climatológicos da reciclagem de precipitação sobre a América do Sul mostram que a contribuição advectiva é mais importante para a precipitação sobre a Amazônia e o Nordeste do Brasil, ao passo que na região Centro-Sul a contribuição local tem importante papel na precipitação. Com base nos resultados dos estudos discutidos, estima-se que a reciclagem de precipitação na bacia amazônica é da ordem de 20-35\%. A advecção de umidade domina o fornecimento de vapor d'água em grande parte da região, entretanto, o papel da evapotranspiração local na reciclagem é mais importante no setor sul da bacia.

A Amazônia demonstra vulnerabilidade às variabilidades e mudanças do sistema climático. O risco dos impactos no ciclo hidrológico regional, na reciclagem de precipitação e, consequentemente, sobre os ecossistemas amazônicos é potencializado quando alterações nos usos da terra em escala regional são acompanhadas por mudanças no clima em escala global. Embora os estudos apresentados tenham quantificado a distribuição da reciclagem de precipitação sobre os continentes, os efeitos das mudanças climáticas globais nesse mecanismo ainda não estão completamente compreendidos.

\section{AGRADECIMENTOS}

Este artigo é parte da Tese de Doutorado do primeiro autor sob orientação do Dr. Fracis Wagner Silva Correia. O primeiro autor agradece ao orientador pela orientação segura e experiente que possibilitou a conclusão do presente trabalho. $\mathrm{O}$ autor também agradece à Coordenação de Aperfeiçoamento de Pessoal de Nível Superior - CAPES pela concessão da bolsa de estudo.

\section{REFERÊNCIAS BIBLIOGRÁFICAS}

ANGELINI, I. M.; GARSTANG, M.; DAVIS, R. E.; HAYDEN, B.; FITZJARRALD, D. R.; LEGATES, D. R.; GRECO, S.; MACKO, S.; CONNORS, V. On the coupling between vegetation and the atmosphere. Theoretical and Applied Climatology, v. 105, n. 1-2, p. 243-261, 2011.

ARRAUT, J. R.; SATYAMURTY, P. Precipitation and water vapor transport in the Southern Hemisphere with emphasis on the South American region. Journal of Applied Meteorology and Climatology, v. 48, n. 9, p. 1902-1912, 2009.

ARRAUT, J. R.; NOBRE, C.; BARBOSA, H. M. J.; OBREGON, G.; MARENGO, J. A. Aerial Rivers and Lakes: Looking at Large-Scale Moisture Transport and Its Relation to Amazonia and to Subtropical Rainfall in South America. Journal of Climate, v. 25, n. 2, p. 543-556, 2012.

ARTAXO, P.; GATTI, L. V.; LEAL, A. M. C.; LONGO, K. M.; FREITAS, S. R.; LARA, L. L.; PAULIQUEVIS, T. M.; PROCPÓPIO, A. S.; RIZZO, L. V. Química atmosférica na Amazônia: a floresta e as emissões de queimadas controlando a composição da atmosfera amazônica. Acta Amazonica, v. 35, n. 2, p. 185-196, 2005.

BOSILOVICH, M. G.; SCHUBERT, S. D. Precipitation Recycling over the Central United States Diagnosed from the GEOS-1 Data Assimilation System. Journal of Hydrometeorology, v. 2, n. 1, p. 26-35, 2001.

BRUBAKER, K. L.; ENTEKHABI, D.; EAGLESON, P. S. Estimation of Continental Precipitation Recycling. Journal of Climate, v. 6, n. 6, p. 1077-1089, 1993.

BRUTSAERT, W. Evaporation Into the Atmosphere: Theory, History and Applications. Massachusetts, USA: D. Reidel, Norwell, 1982. 316p.

BUDYKO, M. I. Climate and Life. New York, USA: Academic Press, 1974. 508p.

CORREIA, F. W. S.; MANZI, A. O.; CÂNDIDO, L. A.; dos SANTOS, R. M. N; PAULIQUEVIS, T. Balanço de umidade na Amazônia e sua sensibilidade às mudanças na cobertura vegetal. Ciência e Cultura, v. 59, n. 3, p. 39-43, 2007.

COSTA, M. H.; FOLEY, J. A. Trends in the hydrologic cycle of the Amazon basin. Journal of Geophysical Research, v. 104, n. D12, p. 14189-14198, 1999.

DOYLE, M. E.; BARROS, V. R. Midsummer low-level circulation and precipitation in subtropical South America and related sea surfasse temperature anomalies in the South Atlantic. Journal of Climate, v. 15, p. 3394-3410, 2002.

DRUMOND, A.; MARENGO, J. A.; AMBRIZZI, T.; NIETO, R.; MOREIRA, L.; GIMENO, L. The role of Amazon Basin moisture on the atmospheric branch of the hydrological cycle: a Lagrangian analysis. Hydrology and Earth System Sciences Discussion, v. 11, n. 1, p. 1023-1046, 2014. 
DRUMOND, A.; NIETO, R.; GIMENO, L. On the contribution of the Tropical Western Hemisphere Warm Pool source of moisture to the Northern Hemisphere precipitation through a Lagrangian approach. Journal of Geophysical Research, v. 116, n. D21, p. 1-9, 2011.

DRUMOND, A.; NIETO, R.; GIMENO, L.; AMBRIZZI, T. A Lagrangian identification of major sources of moisture over Central Brazil and La Plata Basin. Journal of Geophysical Research, v. 113, n. D14, p. 1-9, 2008.

ELTAHIR, E. A. B. A Soil Moisture-Rainfall Feedback Mechanism: 1. Theory and Observations. Water Resour Research, v. 34, n. 4, p. 765-776, 1998

ELTAHIR, E. A. B.; BRAS, R. L. Precipitation recycling in the Amazon basin. Quarterly Journal of the Royal Meteorological Society, v. 120, n. 518, p. 861-880, 1994.

ELTAHIR, E. A. B.; BRAS, R. L. Precipitation Recycling. Reviews of Geophysics, v. 34, n. 3, p. 367-379, 1996.

.FEARNSIDE, P. M. Deforestation in Brazilian Amazonia: History, Rates, and Consequences. Conservation Biology, v. 19, n. 3, p. 680-688, 2005.

FISCH, G.; MARENGO, J. A.; NOBRE, C. A. Uma revisão sobre o clima da Amazônia. Acta Amazonica, v. 28, n. 2, p. 101-126, 1998.

GIMENO, L.; NIETO, R.; DRUMOND, A.; CASTILLO, R.; TRIGO, R. Influence of the intensification of the major oceanic moisture sources on continental precipitation. Geophysical Research Letters, v. 40, n. 7, p. 1443-1450, 2013.

GIMENO, L.; NIETO, R.; VÁZQUEZ, M.; LAVERS, D. A. Atmospheric rivers: a mini-review. Frontiers of Earth Science, v. 2, p. 1-6, 2014.

GIMENO, L.; STOHL, A.; TRIGO, R. M.; DOMINGUEZ, F.; YOSHIMURA, K.; YU, L.; DRUMOND, A.; DURÁNQUESADA, A. M.; NIETO, R. Oceanic and Terrestrial Sources of Continental Precipitation. Reviews of Geophysics, v. 50, n. 4, p. 1-41, 2012.

HELD, I. M.; SODEN, B. J. Robust responses of the hydrological cycle to global warming. Journal of Climate, v. 19, n. 21, p. 5686-5699, 2006.

KALNAY, E.; KANAMITSU, M.; KISTLER, R.; COLLINS, W.; DEAVEN, D.; GANDIN, L.; IREDELL, M.; SAHA, S.; WHITE, G.; WOOLLEN, J.; ZHU, Y.; CHELLIAH, M.; EBISUZAKI, W.; HIGGINS, W.; JANOWIAK, J.; MO, K. C.; ROPELEWSKI, C.; WANG, J.; LEETMAA, A.; REYNOLDS, R.; JENNE, R.; JOSEPH, D. The NCEP/ NCAR 40-Year Reanalysis Project. Bulletin of the American Meteorological Society, v. 77, n. 3, p. 437-471, 1996. MAKARIEVA, A. M.; GORSHKOV, V. G.; SHEIL, D.; NOBRE, A. D.; LI, B. L. Where do winds come from? A new theory on how water vapor condensation influences atmospheric pressure and dynamics. Atmospheric Chemistry and Physics, v. 13, p. 1039-1056, 2013.

MALHI, Y.; ROBERTS, J. T.; BETTS, R. A.; KILLEEN, T. J.; LI, W.; NOBRE, C. A. Climate Change, Deforestation, and the Fate of the Amazon. Science, v. 319, n. 5860, p. 169-172, 2008.

MARENGO, J. A. Characteristics and spatio-temporal variability of the Amazon River Basin Water Budget. Climate Dynamics, v. 24, n. 1, p. 11-22, 2005.

MARENGO, J. A. Interdecadal variability and trends of rainfall across the Amazon basin. Theoretical and Applied Climatology, v. 78, n. 1-3, p. 79-96, 2004.

MARENGO, J. A. On the Hydrological Cycle of the Amazon Basin: a historical review and current state-of-the-art. Revista Brasileira de Meteorologia, v. 21, n. 3a, p. 1-19, 2006.

MARENGO, J. A.; NOBRE, C. A. Clima da Região Amazônica. In: CAVALCANTI, I. F. A.; FERREIRA, N. J.; DA SILVA, M.G.A.J.; SILVA DIAS, M.A.F. (Orgs.). Tempo e Clima no Brasil. São Paulo, SP: Oficina de Textos, 2009. p. 197-212. MARENGO, J.A.; NOBRE, C.A.; CHOU, S. C.; TOMASELLA, J.; SAMPAIO, G.; ALVES L. M.; OBREGÓN, G. O.; SOARES, W. R.; BETTS, R.; KAY, G. Riscos das Mudanças Climáticas no Brasil: análise conjunta BrasilReino Unido sobre os impactos das mudanças climáticas e do desmatamento na Amazônia. Projeto colaborativo realizado pelo Centro de Ciência do Sistema Terrestre (CCST), do Instituto Nacional de Pesquisas Espaciais (INPE), do Brasil e o Met Office Hadley Centre (MOHC), do Reino Unido. Instituto Nacional de Pesquisas Espaciais, São José dos Campos, São Paulo, BRA e Met Office Hadley Centre, U.K.: 2011. 55p.

MARENGO, J. A.; SOARES, W. R.; SAULO, C.; NICOLINI, M. Climatology of the Low-Level Jet East of the Andes as Derived from the NCEP-NCAR Reanalyses: Characteristics and Temporal Variability. Journal of Climate, v. 17, n. 12, p. 2261-2280, 2004.

MARQUES, J.; SANTOS, J. M.; VILLA NOVA, N. A.; SALATI, E. Precipitable water and water vapor flux between Belem and Manaus. Acta Amazonica, v. 7, n. 3, p. 355362, 1977.

MOHAMED, Y. A.; SAVENIJE, H. H. G. Moisture Recycling. The Netherlands: IHE Delft, 2002. 12p.

MOLION, L. C. B. A climatonomic study of the energy and moisture fluxes of the Amazonas basin with considerations of deforestation effects. 1975. Ph.D. Thesis - University of Wisconsin, Madison, USA, 1975.

NOBRE, C. A.; MARENGO, J. A; ARTAXO, P. Understanding the Climate of Amazonia: Progress From LBA. In: KELLER, M.; BUSTAMANTE, M.; GASH, J.; SILVA DIAS, P. 
(Orgs.). Amazonia and Global Change. Geophysical Monograph Ser, vol. 186. Washington, D.C.: American Geophysical Union Books, 2009a. p. 145-147.

NOBRE, C. A.; OBREGÓN, G. O.; MARENGO, J. A; FU, R.; POVEDA, G. Characteristics of Amazonian Climate: Main Features. In: KELLER, M.; BUSTAMANTE, M.; GASH, J.; SILVA DIAS, P. (Orgs.). Amazonia and Global Change. Geophysical Monograph Ser, vol. 186. Washington, D.C.: American Geophysical Union Books, 2009b. p. 149-162.

NÓBREGA, R. S.; CAVAlCANTI, E. P.; SOUZA, E. P. Reciclagem de vapor d'água sobre a América do Sul utilizando reanálises do NCEP-NCAR. Revista Brasileira de Meteorologia, v. 20, n. 2, p. 253-262, 2005.

ROCHA, E. J. P. Balanço de umidade e influência de condições de contorno superficiais sobre a precipitação da Amazônia. 2001. 210f. Tese (Doutorado) - Instituto Nacional de Pesquisas Espaciais - INPE, São José dos Campos - SP, 2001.

ROCHA, H. R.; MANZI, A. O.; SHUTTLEWORTH, J. Evapotranspiration. In: KELLER, M.; BUSTAMANTE, M.; GASH, J.; SILVA DIAS, P. (Orgs.). Amazonia and Global Change. Geophysical Monograph Ser, vol. 186. Washington, D.C.: American Geophysical Union Books, 2009. p. 261-272.

SALATI, E.; DALL'OLIO, A.; MATSUI, E.; GAT, J. R. Recycling of Water in the Amazon Basin: An Isotopic Study. Water Resour Research, v. 15, n. 5, p. 1250-1258, 1979.

SATYAMURTY, P.; da COSTA, C. P. W.; MANZI, A. O. Moisture source for the Amazon Basin: a study of contrasting years. Theoretical and Applied Climatology, v. 111, n. 1-2, p.195-209, 2013.

SAVENIJE, H. H. G. New definitions for moisture recycling and the relation with land-use changes in the Sahel. Journal of Hydrology, v. 167, n. 1-4, p. 57-78, 1995.

SCHAR, C. H.; LUTHI, D.; BEYERLE, U.; HEISE, E. The Soil-Precipitation Feedback: A Process Study with a Regional Climate Model. Journal of Climate, v. 12, n. 3 , p. 722-741, 1999.
SILVA, A. E. Variabilidade da Circulação e Transporte de Umidade no Regime de Monção da América do Sul. 2009. 137f. Tese (Doutorado) - Instituto de Astronomia, Geofísica e Ciências Atmosféricas, Universidade de São Paulo, São Paulo, 2009.

SPRACKLEN, D. V.; ARNOLD, S. R.; TAYLOR, C. M. Observations of increased tropical rainfall preceded by air passage over forests. Nature, v. 489, p. 282-285, 2012.

STENSRUD, D. J. Importance of Low-Level Jets to Climate: A Review. Journal of Climate, v. 9, n. 8, p. 1698-1711, 1996.

TRENBERTH, K. E. Atmospheric Moisture Recycling: Role of Advection and Local Evaporation. Journal of Climate, v. 12, n. 5, p. 1368-1381, 1999.

VAN DER ENT, R. J.; SAVENIJE, H. H. G.; SCHAEFLI, B.; STEELE-DUNNE, S.C. Origin and fate of atmospheric moisture over continentes. Water Resour Research, v. 46, n. 9, p. 1-12, 2010.

VERA, C.; BAEZ, J.; DOUGLAS, M.; EMANUEL, C. B.; ORSINI, J. A. M.; MEITIN, J.; NICOLINI, M.; NOGUESPAEGLES, J.; PAEGLE, J.; PENALBA, O.; SALIO, P.; SAULO, C.; SILVA DIAS, M. A. F.; SILVA DIAS, P.; ZIPSER, E. The South American Low Level Jet Experiment. Bulletin of the American Meteorological Society, v. 87, n. 1, p. 63-77, 2006.

VIANA, L. P.; CORREIA, F. W. S.; FREITAS, S. R. Modelagem do impacto das mudanças no uso da terra na reciclagem de água na Amazônia. In: CONGRESSO BRASILEIRO DE METEOROLOGIA, XVI, 2010, Belém-PA. Anais... Belém: UFPA, 2010. p. 1-5.

ZHU,Y.; NEWELL, R. A proposed algorithm for moisture fluxes from atmospheric rivers. Monthly Weather Review, v. 126, n. 3, p. 725-735, 1998. 